\title{
Control of herpesvirus infection in organ transplant recipients
}

\author{
NINA E TOLKOFF-RUBIN, MD, FACP, ROBERT H RUBIN, MD, FACP, FCCP
}

\begin{abstract}
NE TOLKoff-Rubin, RH RUBIN. Control of herpesvirus infection in organ transplant recipients. Can $J$ Infect Dis 1993;4(Suppl C):59C-64C. The most important causes of infectious disease morbidity and mortality in organ transplant recipients are the herpesviruses, particularly cytomegalovirus (CMV) and Epstein-Barr virus (EBV). Because of their properties of latency, cell association, and potential oncogenicity, they are particularly well suited to causing disease in the transplant patient. Antilymphocyte antibody therapies are potent reactivators of these viruses, and cyclosporine, by inhibiting the critical host defense (virus specific cytotoxic T cells) in a dose-dependent fashion, amplifies the extent and effects of the viral replication. This in turn is translated into clinical disease: fever; pneumonia; gastrointestinal ulcerations; broad-based suppression of host defences leading to opportunistic superinfection and, perhaps, allograft injury in the case of CMV; and B cell lymphoproliferative disease in the case of EBV. New approaches to controlling these viruses in which pre-emptive therapy is linked to immunosuppressive therapy, and new diagnostic techniques for viral monitoring, hold promise for limiting clinical disease due to these viruses.
\end{abstract}

Key Words: Antiviral, Cytomegalovirus, Epstein-Barr virus, Herpesviruses, Immunosuppression, Transplantation

\section{Contrôle de l'infection à herpèsvirus chez les récepteurs de transplantation d'organes}

RÉSUMÉ: Les causes les plus importantes de morbidité et de mortalité liées à la maladie infectieuse chez les receveurs de transplantations d'organes sont les herpèsvirus, particulièrement le cytomégalovirus (CMV) et le virus Epstein-Barr (EBV). À cause de leurs propriétés de latence, d'association cellulaire et d'oncogénicité potentielle, ils sont particulièrement aptes à provoquer la maladie chez les patients qui ont subi une transplantation. Les traitements à l'aide d'anticorps antilymphocytaires sont des réactivateurs puissants de ces virus et la cyclosporine, par l'inhibition des défenses critiques de l'hôte (cellules T cytotoxiques spécifiques au virus) sur un mode dose dépendant, amplifie l'étendue et les effets de la réplication virale. Ce qui, en retour, se traduit par une maladie clinique: fièvre, pneumonie, ulcères gastro-intestinaux, suppression élargie des défenses de l'hôte qui amène la surinfection opportuniste et possiblement des lésions de l'allogreffe dans les cas de CMV et des maladies lympho-prolifératives des cellules B dans les cas de EBV. De nouvelles approches pour maitriser ces virus, parmi lesquelles un type de thérapeutique préventive et le traitement immunosuppresseur, ainsi que de nouvelles techniques diagnostiques de surveillance virale semblent prometteuses pour limiter la maladie clinique attribuable à ces virus. 
$\mathrm{T}$ HE MOST IMPORTANT GROUP OF INFECTIONS AFFECTING transplant recipients is that due to the herpesviruses (1). Although the transplant patient remains susceptible to such community acquired viruses as influenza and parainfluenza (2), hepatitis viruses (3), and even the human immunodeficiency virus (1), the herpesviruses remain the major causes of infectious disease morbidity and mortality in this patient population. These viruses share the following characteristics that make them particularly effective pathogens in this patient population: they cause chronic or latent infection that is modulated by the immunosuppressive therapy being administered to prevent or treat allograft rejection; they may be transmitted through the transfusion of blood, the transplantation of an allograft from an infected donor, or through intimate contact; and the range of clinical effects is extremely broad $(1,4)$. These effects include:

- the direct causation of clinical infectious disease syndromes (eg, fever, pneumonia, hepatitis, gastrointestinal ulcerations);

- the causation of a generalized depression of host defences that is over and above that caused by exogenous immunosuppressive therapy, and which can lead to opportunistic superinfection with such pathogens as Pneumocystis carinii, Listeria monocytogenes, or Aspergillus fumigatus (viruses are important contributors to the net state of immunosuppression);

- the causation of allograft injury by mechanisms separate from classical allograft rejection;

- the causation of certain forms of malignancy (indeed, viral oncogenesis is most clearly seen in transplant patients and those with the acquired immunodeficiency syndrome);

Given the importance of these infections, a great deal of effort has been invested in the prevention and control of viral infections in transplant recipients. This review is a summary of current strategies and future prospects for controlling viral infection in transplant patients; such a summary is based on the following five basic principles $(1,4)$.

Infection and rejection, the two major barriers to successful transplantation, are closely linked. An important truism that underlines clinical management is as follows: any intervention that decreases the risk of infection will permit the safer use of more intensive immunosuppression, thus increasing both patient and allograft survival; conversely, any intervention that decreases the risk of rejection will permit the use of lesser amounts of immunosuppression and decrease the risk of infection, thus increasing patient survival without sacrificing allograft survival.

Risk of infection in the transplant patient is due to the interaction between two factors: the epidemiological exposures that the patient encounters and the patient's net state of immunosuppression (Table 1).

The general pattern of infection with these viruses clinical syndromes, time of onset (in general, particularly for cytomegalovirus [CMV] and Epstein-Barr virus [EBV], one to four months post-transplant), response to therapy, etc - is essentially the same with all the organs transplanted. There is, however, at least one notable exception. In the case of CMV, the organ transplanted is more frequently and more intensely affected than the native organ. Thus, CMV hepatitis is a significant problem essentially only in liver transplant recipients; CMV myocarditis is only recognized in heart transplant recipients; and the attack rate for CMV pneumonia is many times greater in recipients of lung and heart-lung transplants.

Prevention of infection is the primary goal of the infectious disease clinician dealing with transplant recipients. If prevention fails, and clinical infection occurs, then the success of therapy is directly related to the speed with which diagnosis is made and therapy is instituted.

Since immunosuppressive therapy is the major driving force determining the clinical course of the viral infections being considered here, any antimicrobial strategy must be linked to the kind and intensity of immunosuppressive therapy being administered.

\section{HERPESVIRUS INFECTION}

The six human herpesviruses (CMV, EBV, varicellazoster virus [VZV], herpes simplex virus types 1 and 2 [HSV-1 and HSV-2], and human herpesvirus 6 [HHV-6]) share three characteristics that explain their importance in transplant recipients: latency, cell association, and oncogenicity $(1,5)$.

The term latency describes the phenomenon in which primary infection with one of these viruses results in lifelong infection, even after evidence of active viral replication is no longer demonstrable. The laboratory marker of such latent infection is seropositivity. An important clinical issue is the stability of viral latency. Whereas CMV and VZV latency are both quite stable, requiring some event such as the administration of certain forms of immunosuppressive therapy to reactive the virus, EBV and HSV latency are quite unstable, with spontaneous reactivation or reactivation in response to minor stresses being observed. However, even in the cases of EBV and HSV, the same immunosuppressive therapies that reactivate CMV and VZV will increase the rate of reactivation of these viruses. Thus, in the case of EBV, if antilymphocyte antibody therapy is added to cyclosporine-based immunosuppressive programs, the incidence of EBV replication rises from approximately 20 to $30 \%$ to 70 to $80 \%(6,7)$. At present, little is known about HHV-6 infection, other than that evidence of viral replication can be found in approximately half of transplant patients. (Since the clinical 
TABLE 1

Determinants of the net state of immunosuppression in the organ transplant recipient

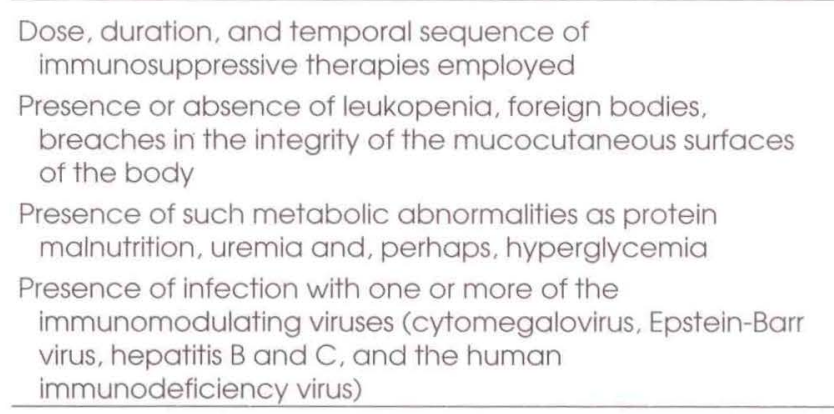

impact of HHV-6 in transplant patients is currently unclear [8], this herpesvirus will not be considered further in this review.)

Herpesviruses are highly cell-associated, meaning spread of virus between individuals requires either intimate mucosal contact, or the physical transfer of the virus (in this case in latent form) via a leukocytecontaining blood product or an allograft. Within the individual, spread and dissemination are via an infected cell to other cells, rendering humoral immunity inefficient and cell-mediated immunity the critical host defence against these viruses. In particular, the key host defence is mediated via virus-specific, major histocompatibility complex restricted, cytotoxic T cells - the limb of host defence most affected by cylcosporinebased immunosuppressive regimens $(1,6)$.

All herpesviruses should be considered potentially oncogenic, although clear-cut clinical evidence to support this has only been demonstrated for EBV, where EBV related $B$ cell lymphoproliferative disease is a clinical problem of increasing importance $(1,6)$.

The clinical effects of these viruses in the transplant patient are delineated in Table 2. In general, primary infection with each of these has a higher attack rate for clinical disease, and a much higher incidence of severe disease. Thus, for CMV the attack rate for clinical disease is two to three times that for primary infection $(1,9)$; for EBV, the incidence of B cell lymphoproliferative disease is many times higher in the setting of primary as opposed to reactivation infection $(7,10)$; primary VZV is a medical emergency, causing pneumonia, encephalitis, hepatitis, pancreatitis, and disseminated intravascular coagulation (and any exposures of VZV seronegative individuals to VZV should result in zoster immune globulin prophylaxis and close monitoring to assess the need for intravenous acyclovir therapy if prophylaxis failure occurs), while reactivation VZV takes the form of dermatomal zoster which rarely disseminates in the organ transplant recipient (11); and primary HSV infection, particularly that conveyed with the allograft, is responsible for the rare cases of disseminated HSV infection occurring in organ transplant
TABLE 2

Clinical effects of herpesviruses in organ transplant recipients

\begin{tabular}{|c|c|}
\hline Virus & Major clinical manifestations \\
\hline Cytomegalovirus & $\begin{array}{l}\text { Fever, pneumonia, hepatitis, gastro- } \\
\text { intestinal ulcerations, chorioretinitis; } \\
\text { immunosuppression; possible } \\
\text { allograft injury }\end{array}$ \\
\hline Epstein-Barr virus & $\begin{array}{l}\text { B cell lymphoproliferative disease; } \\
\text { mononucleosis syndrome: } \\
\text { immunosuppression }\end{array}$ \\
\hline \multirow[t]{2}{*}{ Varicella-zoster virus } & $\begin{array}{l}\text { Primary infection: disseminated } \\
\text { disease with pneumonia, encephalitis, } \\
\text { disseminated intravascular } \\
\text { coagulation, pancreatitis, hepatitis }\end{array}$ \\
\hline & $\begin{array}{l}\text { Reactivation infection: dermatomal } \\
\text { zoster }\end{array}$ \\
\hline \multirow[t]{2}{*}{ Herpes simplex virus } & $\begin{array}{l}\text { Primary infection: mucosal disease } \\
\text { with potential for dissemination }\end{array}$ \\
\hline & $\begin{array}{l}\text { Reactivation infection: oro-facial } \\
\text { (HSV-1) and ano-genital (HSV-2) } \\
\text { mucosal ulcerations }\end{array}$ \\
\hline Human herpesvirus 6 & Unknown \\
\hline
\end{tabular}

recipients (1). Superinfection, that is, when a seropositive individual receives an allograft from a seropositive donor and the virus that is reactivated is of donor origin, has clearly been shown to occur commonly with CMV. Preliminary evidence suggests that superinfection has a greater clinical effect than does endogenous reactivation, although this must still be regarded as an important, incompletely answered question (1,12-15). The role of superinfection with the other herpesviruses, particularly EBV, remains to be established.

\section{EFFECTS OF IMMUNOSUPPRESSION ON HERPESVIRUS INFECTION}

The key factor (other than the donor and recipient's past experience with the virus) that modulates the course of herpesvirus infection is the immunosuppressive therapy that is administered. Following is a summary of the presently available information on this important subject $(1,7)$.

Different immunosuppressive drugs administered in regimens that are equipotent in terms of antirejection effects have very different effects on the two key steps in the pathogenesis of these infections: reactivation from latency, and viral replication and dissemination. Thus, antilymphocyte antibody preparations (both monoclonal and polyclonal) are extremely potent at reactivating herpesviruses, most notably CMV and $\mathrm{EBV}$, from latency. In contrast, corticosteroids, rapamycin, and cyclosporine have no ability to do so. Cytotoxic drugs such as azathioprine and cyclophosphamide are moderately potent in terms of viral reactivation. Once active, replicating virus is present, cyclosporine is extremely potent in terms of amplifying the extent of the viral replication and subsequent dis- 
semination. From these observations, it would be predicted that the immunosuppressive strategy most apt to produce significant clinical effects of CMV and EBV would be the use of an antilymphocyte antibody preparation to prevent or treat rejection, which would reactivate virus, followed by a cyclosporine-based immunosuppressive program which would amplify the extent of the virus. When such a strategy is employed, an effective antiviral program would seem to be necessary $(1,7)$.

These effects of immunosuppressive therapy help explain recent clinical observations with both CMV and $\mathrm{EBV}$ in transplant recipients. When CMV seropositive organ transplant recipients are treated with an immunosuppressive program consisting of cyclosporine, prednisone, with or without azathioprine, the incidence of clinical disease is approximately 10 to $15 \%$. If an antilymphocyte antibody course is added to this program, the incidence of clinical disease rises to approximately $60 \%$. In the case of $\mathrm{EBV}$, a spontaneously reactivating herpesvirus, high dose cyclosporine, with or without low dose prednisone therapy, is associated both with a dose-related inhibition of the specific anti-EBV cytotoxic $\mathrm{T}$ cell surveillance system and a high incidence of lymphoproliferative disease. As doses of cyclosporine are decreased, the surveillance system becomes more effective and the incidence of lymphoproliferative disease decreases. However, when such antilymphocyte antibody preparations as OKT3 are used, the incidence of lymphoproliferative disease increases markedly. In both these instances, the antilymphocyte antibody reactivates latent virus, and the cyclosporine amplifies the extent of this virus. In the case of CMV, such clinical syndromes as fever, pneumonia, hepatitis, and gastrointestinal ulcerations, opportunistic superinfection, and, perhaps, allograft injury are produced; in the case of EBV, the major effect is the development of lymphoproliferative disease. It should be emphasized that these observations were made in patients not receiving antiviral prophylaxis $(1,7,9,16)$.

\section{ANTIVIRAL STRATEGIES IN TRANSPLANT RECIPIENTS}

Antiviral strategies against this group of viruses is clearly indicated. When considering these strategies, it should be emphasized that there are three different modes in which antimicrobial therapies can be administered to the transplant patient: therapeutic, prophylactic and pre-emptive. In therapeutic mode, antimicrobial agents are administered to treat established disease; in prophylactic mode, nontoxic antimicrobial agents are administered to all individuals to prevent an infection that is both common enough and important enough to merit such an approach; and in pre-emptive mode, antimicrobial agents are administered to a subgroup of patients prior to the appearance of clinical disease. The initiation of pre-emptive therapy is based on the identification of a laboratory marker or patient characteristic that identifies that subgroup of individuals with the highest risk of serious disease at a time when antimicrobial intervention would be maximally effective in terminating the disease process $(17,18)$.

Therapeutically, intravenous ganciclovir (at a dosage of $5 \mathrm{mg} / \mathrm{kg}$ twice daily for two to three weeks, with modification of the dosage in the face of renal dysfunction) has been shown to be quite effective in the treatment of symptomatic CMV disease (it is effective against VZV and HSV as well, although the less toxic acyclovir will suffice against these if CMV is not an issue). Based on studies in a murine CMV model and in the treatment of CMV pneumonia in bone marrow transplant recipients in whom the addition of CMV hyperimmune immunoglobulin to ganciclovir therapy significantly improved patient survival, many clinicians would use the combined regimen in organ transplant patients with severe CMV disease, particularly pneumonia, or those with relapsing disease. It is important to emphasize that ganciclovir-resistant CMV infection, a common event in patients with advanced acquired immunodeficiency syndrome (AIDS) being treated for CMV infection, has not been a problem thus far in organ transplant recipients. Thus, experience with foscarnet therapy, the treatment of choice for ganciclovir-resistant CMV in AIDS patients, is as yet quite minimal $(1,17)$.

Given the protean manifestations of CMV in the transplant patient, prevention of clinical disease would be far more appealing. Although proscribing the use of organs from CMV seropositive donors for CMV seronegative patients would prevent primary CMV infection (provided either CMV-negative blood products or an effective leukocyte filter is used to prevent CMV transmission via this route), this strategy has not been widely used for two reasons: it would limit the already inadequate supply of donors; and seropositive recipients of allografts from seropositive donors may also be penalized because of the risk of superinfection. Therefore, an effective antiviral strategy is preferred $(1,9,17)$. Studies of high dose oral acyclovir (approximately 3200 mg/day for four to six months) $(19,20)$ and hyperimmune CMV immunoglobulin (administered multiple times over the first four to six months post transplant) (21) given separately to kidney allograft recipients at risk for primary infection have shown a decrease in disease of approximately 50\% (17). However, these regimens, as well as intravenous ganciclovir administered for one month post-transplant, have been ineffective in preventing primary CMV disease in heart, liver, and lung recipients $(1,17,22)$. In addition, the benefits of these two regimens are greatly attenuated in the face of antilymphocyte antibody antirejection therapy. Recently, the Halifax group (23) reported that lower doses of both these agents given together is probably more effective than either alone, but their benefit is greatly decreased in the face of antilymphocyte antibody therapy. 
Several lessons of importance have come out of this prophylactic experience: first, it is clear that with the antiviral agents currently available, a standard prophylaxis program for all patients will have to be modified to fit with the demands of antirejection immunosuppressive therapy. Second, it would appear that CMV, as it first emerges from latency, is far more susceptible to antiviral manipulations than fully established CMV clinical infection. For example, acyclovir, to which CMV is relatively resistant, has the aforementioned efficacy prophylactically but not therapeutically (17).

The present sudy took a different approach to prevention of CMV disease. Impressed by the threefold increase in incidence of clinical disease among seropositive individuals treated with antilymphocyte antibodies, and with the recognition that only 20 to $30 \%$ of patients required OKT3 therapy to reverse rejection, we questioned whether an antiviral strategy triggered by the initiation of OKT3 therapy could be successful. In other words, pre-emptive therapy was geared to the initiation of the antirejection therapy that was responsible for the excessive number of cases of clinical CMV. In this approach, a single daily dosage of ganciclovir (2.5 $\mathrm{mg} / \mathrm{kg} /$ day) was administered along with each daily dose of OKT3. The incidence of CMV disease was decreased from 60 to $10 \%(1,16)$.

Recent experience in bone marrow transplant recipients suggests an additional indication for triggering pre-emptive therapy. In these studies, ganciclovir therapy was initiated when asymptomatic viral replication was demonstrated, with viremia probably being the best accessible marker that can be monitored. Such pre-emptive therapy was quite successful in preventing the occurrence of CMV pneumonia, a dreaded event in bone marrow transplant recipients (24). With the advent of an assay for CMV antigenemia (25) and polymerase chain reaction techniques $(25,26)$ for same-day detection of viremia, it is likely that pre-emptive therapy

\section{REFERENCES}

1. Rubin RH. Infection in the organ transplant recipient. In: Rubin RH, Young LS, eds. Clinical Approach to Infection in the Compromised Host, 3rd edn. New York: Plenum Medical Book Co. (In press)

2. Apalsch AM, Green M, Wald ER. Influenza and parainfluenza virus infections in pediatric organ transplant recipients. 32nd Interscience Conference on Antimicrobial Agents and Chemotherapy. Anaheim, 1992;27. (Abst)

3. Katkov WN, Rubin RH. Liver disease in the organ transplant recipient: Etiology, clinical impact, and clinical management. Transplantation Review 1991;5:200-8.

4. Rubin RH, Wolfson JS, Cosimi AB, Tolkoff-Rubin NE. Infection in the renal transplant recipient. Am J Med 1981;70:405-11.

5. Ho M. Virus infections after transplantation in man: Brief review. Arch Virol 1977;55:1-24.

6. Cheeseman SH, Henle W, Rubin RH, et al. Epstein-Barr virus infection in renal transplant recipients: Effects of anti-thymocyte globulin and interferon. Ann Intern Med based on the asymptomatic detection of viremia should be feasible - not in place of the therapy with OKT3, but as a 'fail safe' for patients who break through that preventive approach.

The recent publication by Preiskaitis et al (7) on EBV replication and the subsequent development of EBVrelated lymphoproliferative disease suggests that this same immunosuppression related antiviral approach could be effective in preventing these dire consequences of EBV disease. The following observations are important in this regard: they and others (6) have related the incidence of EBV activation and subsequent lymphoproliferative disease development to the use of antilymphocyte antibody treatment; quantitative EBV virology studies revealed that the incidence of lymphoproliferative disease is directly related to the level of EBV replication in the pharynx, being particularly high in patients with primary EBV infection and those treated with antilymphocyte antibodies; and, of great importance, treatment with either ganciclovir or acyclovir terminated EBV replication. Thus, the possibility exists that the same pre-emptive strategy used to control CMV would be effective in limiting the effects of EBV infection (17).

Considerable progress has been made in the control of herpesvirus infection. Prophylactic strategies are at least partially effective. However, the most important lesson learned is that any preventative strategy must be linked to the immunosuppressive program being administered to the particular patient. Thus, pre-emptive strategies, linked to the immunosuppression and backed up by close viral monitoring, are the key to the future control of these infections. The principle has now been clearly established that the therapeutic prescription for the transplant patient has two parts: an immunosuppressive strategy to prevent or treat rejection, and an antimicrobial strategy to make it safe. We now have the tools to control this most important class of infection in transplant recipients $(1,17)$.

$1980 ; 193: 39-42$.

7. Preiksaitis JK, Diaz-Mitoma F, Mirzayans F, Robert S, Tyrrell DLJ. Quantitative oropharyngeal Epstein-Barr virus shedding in renal and cardiac transplant recipients: Relationship to immunosuppressive therapy, serological responses, and the risk of post-transplant lymphoproliferative disorder. J Infect Dis 1992;166:986-94.

8. Yoshikawa T, Suga S, Asano Y, et al. A prospective study of human herpesvirus-6 infection in renal transplantation. Transplantation 1992;54:879-83.

9. Rubin RH. Impact of cytomegalovirus infection on organ transplant recipients. Rev Infect Dis 1990;12 (Suppl 7):S754-66.

10. Ho M, Miller G, Atchison RW, et al. Epstein-Barr virus infection and DNA hybridization studies in posttransplantation lymphoma. Infect Dis $1985 ; 152: 876-86$.

11. Lynfield R, Herrin JT, Rubin RH. Varicella in pediatric renal transplant recipients. Pediatrics 1992;90:216-20.

12. Chou S. Acquisition of donor strains of cytomegalovirus 
by renal transplant recipients. N Engl J Med 1986:314:1418-23.

13. Grundy JE, Lui SF, Super M, et al. Symptomatic cytomegalovirus infection in seropositive patients: Reinfection with donor virus rather than reactivation of recipient virus. Lancet 1988;ii:132-5.

14. Fryd DS, Peterson PK, Ferguson RM, Simmons RL, Balfour HH Jr, Najarian JS. Cytomegalovirus as a risk factor in renal transplantation. Transplantation 1980;30:436-9.

15. Smiley ML, Wlodaver CG, Grossman RA, et al. The role of pretransplant immunity in protection from cytomegalovirus disease following renal transplantation. Transplantation 1985;40:157-61.

16. Hibberd PL, Tolkoff-Rubin NE, Cosimi AB, et al. Symptomatic cytomegalovirus disease in the cytomegalovirus antibody seropositive renal transplant recipient treated with OKT3. Transplantation 1992;53:68-72.

17. Rubin RH, Tolkoff-Rubin NE. Antimicrobial strategies in the care of organ transplant recipients. Antimicrob Agents Chemother 1993;37:619-24

18. Rubin RH. Preemptive therapy in immunocompromised hosts. N Engl J Med 1991;324:1057-9.

19. Balfour HH Jr, Chace BA, Stapleton JT, et al. A randomized, placebo-controlled trial of oral acyclovir for the prevention of cytomegalovirus disease in recipients of renal allografts. N Engl J Med 1989;320:1381-7.
20. Balfour HH Jr. Prevention of cytomegalovirus disease in renal allograft recipients. Scand J Infect Dis 1991:Suppl 78:88-93.

21. Snydman DR, Werner BG, Heinze-Lacey B, et al. Use of cytomegalovirus immune globulin to prevent cytomegalovirus disease in renal transplant recipients. N Engl J Med 1987;317:1049-54.

22. Merigan TC, Renlund DG, Keay S, et al. A controlled trial of ganciclovir to prevent cytomegalovirus disease after heart transplantation. N Engl J Med 1992;326:1182-6.

23. Nicol DL, MacDonald AS, Belitsky P, et al. Reduction by combination prophylactic therapy with CMV hyperimmune globulin and acyclovir of the risk of primary CMV disease in renal transplant recipients. Transplantation 1993;55:841-6

24. Goodrich JM, Mori M, Gleaves CA, et al. Early treatment with ganciclovir to prevent cytomegalovirus disease after allogeneic bone marrow transplantation. N Engl J Med 1991;235:1601-7.

25. The TH, van der Ploeg M, van der Berg M, et al. Direct detection of cytomegalovirus in peripheral blood leukocytes - A review of the antigenemic assay and polymerase chain reaction. Transplant 1992:54:193-8.

26. van Dorp WT, Vlieger A, Jiwa NM, et al. The polymerase chain reaction, a sensitive and rapid technique for detecting cytomegalovirus infection after renal transplantation. Transplantation 1992;54:661-4. 


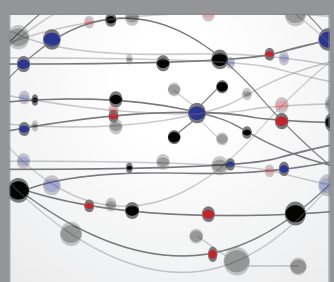

The Scientific World Journal
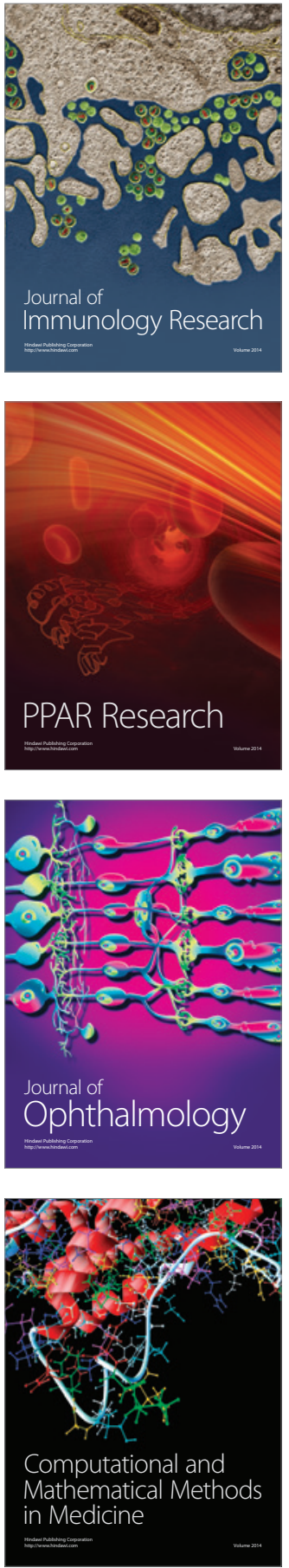

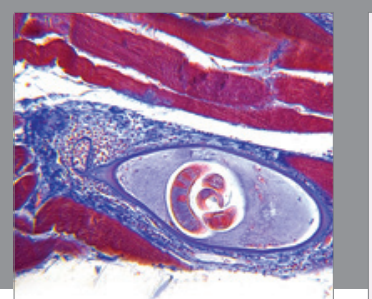

Gastroenterology Research and Practice

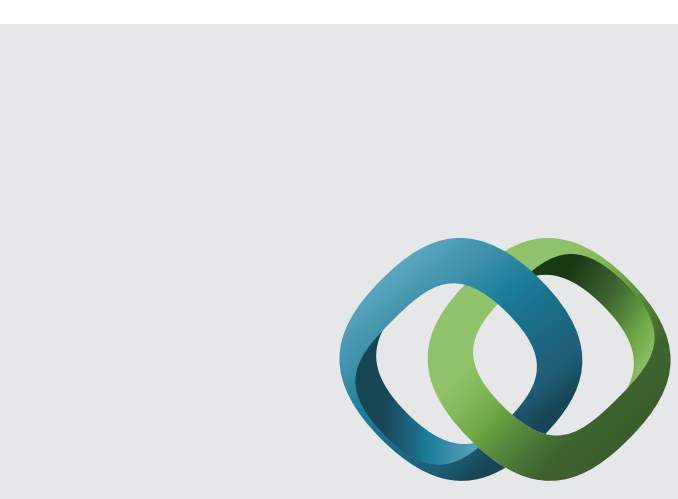

\section{Hindawi}

Submit your manuscripts at

http://www.hindawi.com
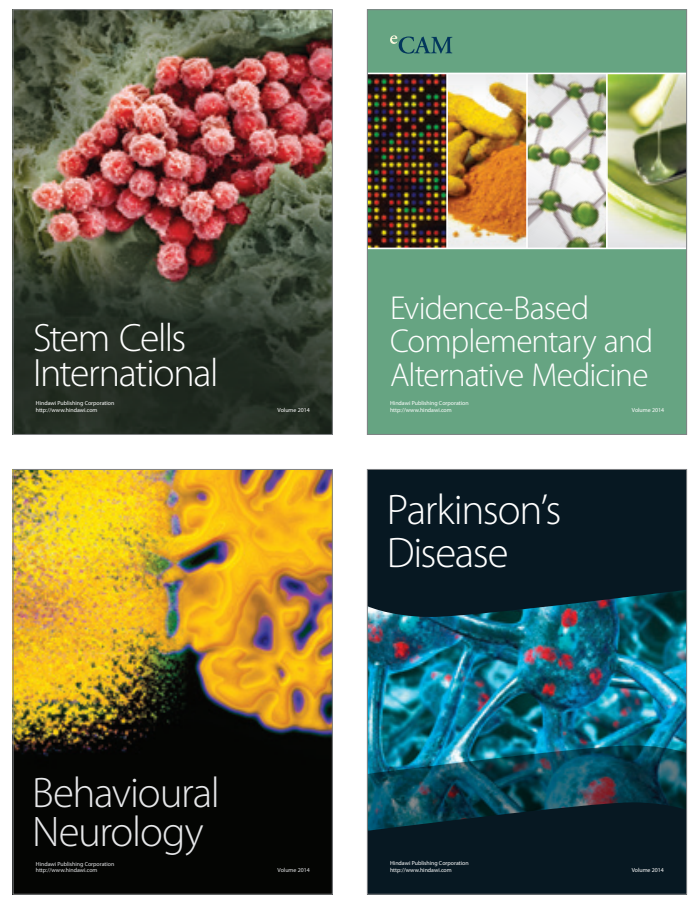
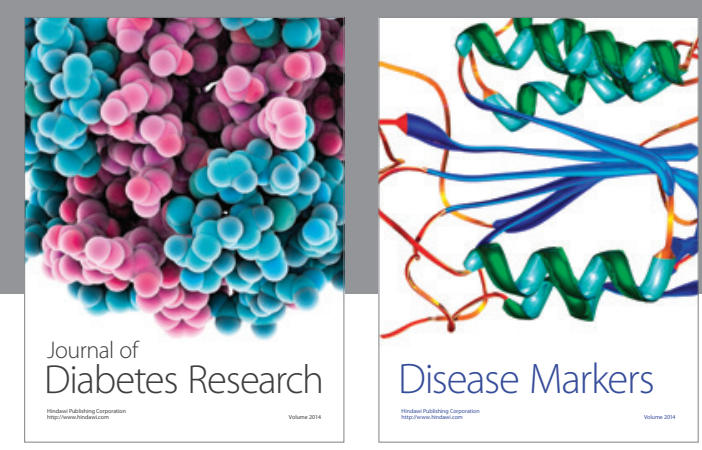

Disease Markers
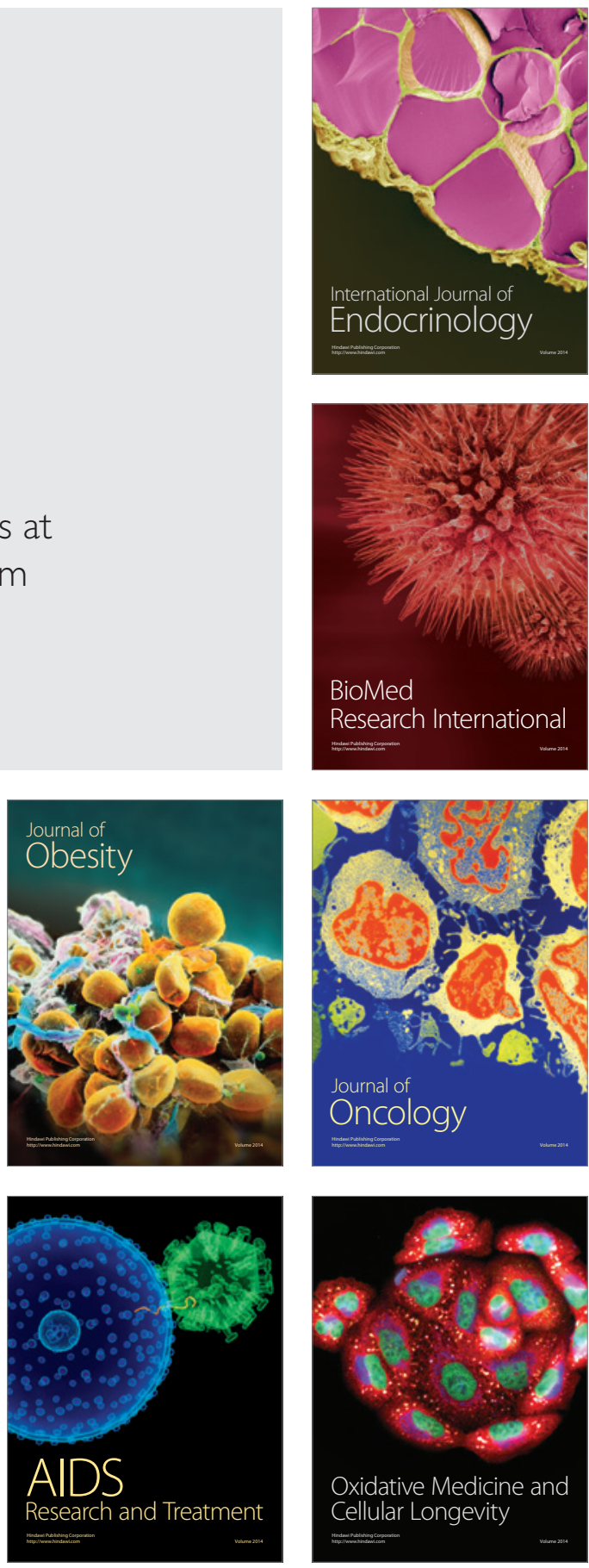